\title{
A Systematic Review on The Leading Causes of Death Among Under- Five Children in Iran
}

Badrye Karami

Tehran University of Medical Sciences

Mahya Abbasi

Tehran University of Medical Sciences

Maryam Tajvar ( $\square$ mtajvar@tums.ac.ir)

Tehran University of Medical Sciences

\section{Research article}

Keywords: Child Mortality, Infant Mortality, Neonatal Mortality, under 5 mortality, ICD-10

Posted Date: December 23rd, 2020

DOI: https://doi.org/10.21203/rs.3.rs-132227/v1

License: (1) This work is licensed under a Creative Commons Attribution 4.0 International License. Read Full License 


\section{Abstract}

Background: Child mortality is one of the most important indicators of population health. No systematic review has explored the leading causes of death among under-five children in Iran. This study reviewed the causes of child death by different age groups on the basis of ICD-10.

Methods: A systematic search in seven electronic databases and two search engines of all the studies that identified causes of child mortality in any part of Iran or in the whole country were included, without any restriction of time or language of studies. To identify the studies, a combination of hand searching, gray literatures and bibliographies was also conducted. These sources and citations yielded a total of 817 articles; nevertheless, finally 30 articles fulfilled the inclusion criteria, then were reviewed and analyzed.

Results: Amongst the 30 studies published between 2000 and 2019 in Iran, 25 studies were cross-sectional and 19 published in Farsi language. Overall, 71244 child deaths in different age ranges were reviewed in this study. The most common causes of "neonatal mortality" were prenatal conditions (57.8\%), congenital malformations, deformations, and chromosomal abnormalities (17\%) and disorders of length of gestation and fetal growth (5.9\%). "Infant mortalities" were also mainly happened as a result of congenital malformations (22.8\%), remainder of prenatal condition (21.2\%) and remainder of diseases of the respiratory system (9\%). In the age range of 28 days to 5 years, transport accidents (21.1\%), congenital malformations $(18.1 \%)$ and neoplasms $(9.3 \%)$ were common leading causes of' deaths. Overall, certain conditions originating in the perinatal period $(29.3 \%)$, all other disease $(26.1 \%$ ) and external diseases $(5.6 \%)$ were the leading cause of death in under-five children.

Conclusions: This study, provided an updated summary of evidences on the causes of child death in Iran, which is highly critical for the development of interventions and reduction of the burden of under 5 mortality and morbidities.

\section{Plain English Summary}

Child mortality is one of the most important health indicators in society. Various factors play a role in determining this indicator, the most important of which are the health, socioeconomic, political and cultural status of the community. Investigating the causes of death of children is essential in understanding the significant determinants and then in health policymaking and planning further interventions.

In this study, for assessing cause of death in under five mortalities, we did a systematic review of all the previous evidences. The finding of the assessed studies indicated that death due to prenatal conditions and congenital malformations, deformations, and chromosomal abnormalities were most common causes of death in under 5 years. In addition, studies have highlighted the important role of all other diseases, external factors, transport accidents and neoplasms in child mortality in Iran. In summary, the vast majority of conditions and diseases, which lead to death among children under five years of age, are preventable or curable through cost-effective interventions. Therefore, it is necessary to understand more on the causes of death, designing interventions, educate parents and children, and improve parents' awareness about the signs and symptoms of diseases in order to reduce child mortality.

\section{Background}

Child mortality is often used as an indicator of population health and well-being as well as the overall development in countries (1). The under-5 mortality rate (U5MR), which is defined as the probability of dying between birth and exactly 5 years of age, expressed per 1,000 live births (2), has been identified as one of the key indicators of population health $(3,4)$. The U5MR has been considered as one of the aims in the United Nation 2015 Millennium Development Goals (MDGs). Despite significant progress in the reduction of child mortality since 1990, the goal of stopping preventable deaths of children younger than 5 years by 2030 was again reflected in the Sustainable Development Goals (SDGs) (5-9).

In 1990, Neonatal Mortality Rate (NMR), Infant Mortality Rate (IMR), and the U5MR were accounted as 37, 65 and 93, respectively, in the world, which declined to 18, 29 and 39 by 2017 (5). In Iran, the U5MR has been reduced remarkably since last two decades, by establishing health care networks and increasing the access of urban and rural population to primary health services and public health programs (6). As a result, the U5MR in Iran was reduced from 58 in 1990 to only 15 in 2016 (5), and now is among the 106 countries in the world with an U5MR under 100 (7). Nevertheless, despite this considerable achievements, there is a considerable inequality in the rate of child mortality among different provinces and areas in Iran and thus its major causes and determinant factors are still worthy of consideration $(8,9)$.

Based on International Classification of Diseases (ICD-10), introduced by the World Health Organization (WHO), the underlying causes of death have been defined as; " (a) a disease or injury that initiated the train of morbid events leading directly to death, or (b) the circumstances of the accident or violence that led to fatal injury. However, special rules may apply to certain diseases or injuries" (10). The main causes of death among children under 5 years old in 2016 were preterm birth complications (18\%), pneumonia (16\%), intrapartum-related events (12\%), and congenital anomalies (9\%) (11).

In Iran, there are various studies and reports for causes of the U5MR for different areas at provincial or city level, but for whole country there are inconsistent data or the data are available for some specific age groups of children for a limited time (12-16). While, efforts to increase the 
chance of survival in children are based on accurate data and information on the causes of child mortality (8). Therefore, a comprehensive review study was required to collect and review all the available evidences in Iran, in order to reach to a clear picture of causes of child mortality. This review study aimed to provide insights into the causes of child mortality by different age groups in Iran, based on the ICD-10. Identifying the causes of death is a key step in improving child survival by knowing modifiable factors to prioritizing interventions, recognizing the effectiveness of disease-specific interventions and assessing the needs and burden of disease in relation to national and international goals (17). It is hoped that the results of this review study would build an information basis for development such interventions for preventing child mortality and promoting child health.

\section{Methods}

\section{Criteria for considering studies for this review}

This review considered all studies that assessed causes of under-five mortalities in Iran. For "Under-Five Mortality", we considered the definition of the WHO, as the probability of dying between birth and exactly 5 years of age, expressed based on 1,000 live births. The Under-Five Mortality, itself was categorized into other sub-groups including Neonatal Mortality Rate (NMR), the probability of dying in the first 28 days of life, expressed based on 1,000 live births, and Infant Mortality Rate (IMR), as the probability of dying between birth and exactly age of one year, expressed based on 1,000 live births (18). It should be noted that since some of the original studies in Iran focused on the age groups out of the standard categorization, as mentioned above, we had to integrate them together to be able to follow the above age-categorization. For example, the studies that considered the causes of death in the age of 28 days -one year old, were integrated with the studies considered the age group from birth to one year old. In addition, studies with the age group of 1 year -5 years old were integrated with the studies with the age group of 28 days - 5 years old. Finally, were grouped all the studies into 4 age groups as shown in Table 2.

In the search for studies, no restrictions were considered regarding the date of publication, time or language.

\section{Search strategy}

Reviews of literature were conducted based on the inclusion criteria, first in the following electronic databases: "PubMed”, "Scopus", "Cochrane library databases", "Web of Science" "Google” and "Google scholar”. The last search was carried out on May 19, 2020.

As shown in Table 1, in PubMed and Cochrane library databases, we initially performed the search using MeSH terms. In other databases, all the synonyms for "Under-Five Child Mortality" were searched and afterward, "Iran" was also added to the search terms. This method was the most appropriate way of searching for making sure that no study were missed out due to term restrictions.

To ensure that all relevant studies including those published in Farsi (official language of Iran) were identified, an electronic search was conducted in Farsi in "Google" and "Google scholar" as well as in major national databases, including "SID" and "Magiran", using the translation of "under-five mortality" and its various synonyms in Farsi and also the word "Iran" as keywords. Additional search was also performed for the bibliographies of the included studies. Reference lists of selected articles were also screened for additional publications. The main experienced authors in the field of study were identified and they were contacted to find the most relevant surveys. In a similar way, hand-searching was conducted among highly relevant journals, grey literature, informal reports and documentation by the government or other agencies, theses, research projects, etc. All studies from different sources were imported into EndNote $\times 8$.

\section{Selection of studies}

The following PRISMA Flow diagram shows the process of identifying, reviewing, and selecting articles in this review. Studies that only considered a specific cause of child mortality, or examined the child mortality in a place smaller than a city, or only reported descriptive statistics on child mortality were excluded from the review.

Initially, 817 surveys were obtained through electronic and hand-searching. All duplicated records ( $\mathrm{n}=101)$ were removed before title and abstract screening process and 716 records remained for further review. Then, the titles and abstracts of the remaining articles were examined subsequently, and irrelevant papers were removed. Finally, a total of 136 citations were obtained for full text review to assess their eligibility. 74 studies that only described one specific cause of death, or focused on a smaller setting than city or only reported prevalence of child mortality were excluded. Finally, 30 studies met the inclusion criteria for this review article, and were hence utilized.

\section{Quality assessment}

Two reviewers appraised all selected studies independently. Appraisal was done by STROBE checklist including 22 items (score range: $0-22$ ) (19), which assesses the lucidity of the objectives and research questions of cohort, case-control, and cross-sectional (combined) studies. The reviewers excluded all articles that scored lower than 16 in quality assessment. Since the number of articles in this field is high, it seemed to be able to stay on high quality articles by selecting this cut-point. In cases of disagreement between reviewers, the dispute was resolved through 
consultation and reaching an agreement. Meeting abstracts and editorial letters were excluded, too. The STROBE scores of the final included papers are reported in Table 2.

\section{Data extraction and analysis strategy}

The required data, including the reported causes associated with child mortality were extracted from the articles using a purposefully designed data extraction form. We used the following age groups to explore mortality: first 28 days of life (Neonate); 28 days to exactly one year of age (Infant), birth to exactly 5 years of age (under 5) and 28 days to 5 years. Furthermore, items including first author's name, language, publication date, sample, setting, time, design, analysis, findings, and quality score were also extracted (Table 2).

The studies included here were developed based on multiple objectives, used a variety of measures and methods and included study participants with different characteristics. This diversity made formal meta-analysis impossible. Therefore, the results of causes of death in the mentioned age groups were identified and grouped together and the findings were then reported, compared and examined descriptively. Nationally, some categories of child deaths, particularly neonatal and infant deaths, including sudden unexpected deaths in infancy, accidents and injuries, and maltreatment-related deaths vary by region, ethnic origin, and socioeconomic status (20). In Iran, deaths are coded according to the ICD-10, which, categories causes into 15 disease groups, with specific disease groups in every category.

\section{Results}

\section{Description of the included studies}

In this review study, 30 original studies were included, which reviewed 71244 child death in overall. Of all the included studies, 25 studies (83.5\%) were cross-sectional and others were case-control studies. Similarly, 19 out of the 30 papers (63.3\%) were written in Farsi and the others in English. The publication date of the included studies ranged from 2000 to 2019 . Moreover, out of these 30 studies, 4 studies were conducted at country level, 15 studies at provincial level and 11 studies at city level (Fig 2). With regard to the place of child death in the studies, $56.6 \%$ happened in hospitals, $13.3 \%$ in healthcare centers, and $9.9 \%$ in a health facility, but didn't mentioned which facility. In $20 \%$ of the studies, the exact location of death was not mentioned and "all/any place" was considered. The figure 3 shows the number of studies by different age groups and as appears, most of the studies were conducted in the age group of 0-28 days (Neonates).

\section{Causes of child deaths in Iran}

As mentioned, in this review article overall 71244 child death were reviewed, of which, 18567 (26\%) deaths were in the age range of $0-28$ days, $8332(11.7 \%)$ were in the age range of $0-1$-year-old, $43811(61.5 \%)$ were in the age of $0-5$ years old and $534(0.8 \%)$ were in the age of 28 days-5 years old. The source of data collection for 29 out of the 30 studies on the causes of death was based on the Child Mortality Surveillance System (CMSS) of Iran. The data source of another one was based on the causes of death recorded in Legal Medicine Research Center. As shown in Table 3, more than half of under 28 days' deaths occurred due to prenatal conditions. Also, two major causes of death of more than $40 \%$ of infant mortality were due to congenital malformations and Remainder of perinatal conditions. Causes such as "all other diseases" and "certain conditions originating in the perinatal period" were responsible of more than $50 \%$ of deaths in older ages. Studies also showed that "transport accidents" had a significant role in deaths of children in age of 28 days to 5 years' old.

Due to the fact that the causes reported in some of the studies are not exactly included in any of the subgroups of causes of death, based on the nature of the cause, the title of causes of death was provided instead of its subgroup. As a result, the following figures has been prepared based on the combination of the main causes and its subgroups. As figure 4-A shows, the main causes of death in children 0-28 days old (Neonatal mortality) were remainder of perinatal condition (57\%), congenital malformation (17\%), disorders relating to length of gestation and fetal growth (5.9\%), remainder of disease of respiratory system (4\%) and all other diseases (2.3\%). In under 1 year old (infant mortality), five common causes of death were congenital malformation (22.8\%), remainder of perinatal condition (21\%), remainder of disease of the respiratory system (9\%), transport accidents (5.7\%), and certain infection and parasite diseases (5.6\%) (Fig 4-B). Additionally, in under 5 years old, certain condition originating in the perinatal period (29.3\%), all other diseases (26.1\%), endocrine, nutritional and metabolic diseases (5.3\%), transport accidents $(5 \%)$, diseases of the circulatory system (4.5\%), were respectively major causes of death (Fig 4-C). In addition, most important causes of death in 28 days -5 years were transport accidents (21.1\%), congenital malformation (18.1\%), neoplasm (9.3\%), diseases of the nervous system (8.2\%) and remainder of disease of the respiratory system (7.8\%) (Fig 4-D).

\section{Discussion}

The aim of this study was to investigate the causes of under- 5 mortalities in Iran. Overall, thirty original studies examined the causes of under-5 children death in different age groups. Understanding the causes of child mortality is of particular importance for implementing specific interventions for each age group in order to effectively reduce the burden of mortality and its complications in the country. The results of studies showed that death due to prenatal conditions was one of the three most common causes of death in the age groups 0 to 28 , under one year and 
under 5 years. Disorders related to length of gestation and fetal growth was another most important cause of death in children 28 days, which has not been reported as a major cause in other age groups. Deaths are often due to neonatal factors such as birth weight and age, infant's sex, factors during childbirth such as abnormal cessation of labor, lack of midwifery care, asphyxia, and long-term gestation. The health status of the mother during pregnancy also has a significant effect on the life and death of the child $(21,22)$. To reduce these issues, developing and equipping maternity hospitals and providing access to trained maternity staff, developing neonatal care centers and providing access to intensive care for high-risk infants, and to promote prenatal care such as screening and premarital genetic tests, as well as development of effective programs with emphasis on reducing pregnancies under 18 years and over 35 years is recommended.

Congenital malformations, deformations, and chromosomal abnormalities are also some of the most important causes of death in the age groups of first 28 days of life, under 1 year and the age between 28 days to 5 years. About $20 \%$ of infant deaths are due to congenital anomalies at birth. In general, between $3 \%$ and $5 \%$ of infants have detectable birth defects. Genetic and environmental factors or both cause these disorders. Various factors such as medications, infections and various diseases, injuries, smoking, malnutrition, pregnancy after 35 years of age and exposure to radiation during pregnancy are the most important causes of these disorders (23-25). Treatment and rehabilitation of people with disabilities due to congenital anomalies imposes a huge cost on society. On the other hand, some severe congenital anomalies cause abortion or intrauterine death. As a result, recognizing and preventing congenital anomalies will be more cost-effective for communities than treatment (26). Given the high prevalence of consanguineous marriages in Iran, the role of premarital counseling should receive more attention to prevent the birth of abnormal children.

Respiratory illnesses and diseases were another major cause of death in the age group under one year of age. Nine million children under 5 years of age die annually and lung diseases are the most common causes of these deaths. Pneumonia is the world's leading killer of young children. Asthma is the most common chronic disease, affecting about $14 \%$ of children globally, which has a rising trend $(27,28)$. Childhood respiratory disease can be prevented or ameliorated by several basic measures: improving childhood nutrition, promoting breastfeeding, ensuring comprehensive immunization, improving living conditions to prevent crowding, avoiding tobacco smoke exposure, reducing indoor air pollution, and treating HIV and preventing mother-to-child HIV transmission (29).

Studies examining the causes of death in the under- 5 age group have highlighted the important role of all other diseases and external factors. All other diseases include causes of death that are not categorized in other ICD-10 classifications. For example, diseases related to the kidney system. External causes are also defined as the harm caused by physical or chemical agents or other factors including medical malpractice and death from criminal intent (30). Improving care processes, proper education and development of appropriate instructions, reducing the volume and working hours of health workers and establishing committees to control and monitor their performance and error reporting system, promoting patient safety culture, educating families about routine medical cares and identifying risks in their living environment can provide the basis for lower child mortality.

The vast majority of conditions and diseases which lead to death among children under five years of age are preventable and treatable through cost-effective interventions (31). Given that children have no role in creating theses causes and death and disability is often due to mistakes made by adults, and in order to provide better care for children, giving the necessary information to parents and other family members in this regard can reduce the number of external factors (32).

Also in the age group of 28 to 5 years, transport accidents are the most common cause of death and neoplasms account for a high percentage of child deaths. Unintentional accidents are one of the problems that can be improved with the help of a wide range of individuals and groups. In order to reduce the death rate caused by these accidents, public awareness and the application of serious laws and regulations in this field can be effective (33). Motor vehicles are a major cause of death for many children in the United States, and one of the four reported causes of death for children under 14 years of age. The results of a study in the United States showed that more than 2355 children have been killed and injured in traffic accidents in 2004 (34).

Childhood cancers are more common in two age groups, one in early childhood and another in adolescence. In the early years of life, embryonic tumors such as neuroblastoma, Wilms tumor, retinoblastoma, rhabdomyosarcoma, medulloblastoma are the most common tumors. In the age range of 2-5 years, in addition to fetal tumors, acute leukemia, non-Hodgkin's lymphomas and gliomas are the most common (35). Due to the process of cancer treatment in children, it is necessary to pay attention to the quality of life in this group. According to studies, many factors can possibly reduce the quality of life of cancer patients. By identifying these factors that increase the symptoms of anxiety in cancer patients, we can plan to improve the short-term and long-term quality of children's life (36).

It is critical to address the main causes of neonatal mortality, which often differ from the causes of under-5 mortalities. Preterm birth, intrapartum-related complications (birth asphyxia or lack of breathing at birth), infections and birth defects caused most neonatal deaths in 2018 , as shown in Figure 5. The vast majority of newborn deaths take place in low- and lower-middle income countries. As neonatal mortality rates decline in higher-income countries, causes other than intrapartum-related causes and sepsis become significant in further reduction of neonatal 
mortality. Congenital anomalies and prematurity are the leading causes of neonatal death in higher-income countries. Moreover, three major causes of deaths among children aged 1-59 months in the world were pneumonia, other diseases and diarrhea (Fig 5) (37).

\section{Conclusion}

Based on the results of this review, many studies have been conducted in Iran, but no study has systematically reviewed the results of those. The aim of this study was to investigate the causes of death of children under 5 years old in Iran. Overall, 71244 deaths were reviewed in this study. The results showed that the most important causes of death were different in various age groups under 5 years old. Among children 0 -28 days, remainder of perinatal conditions were the leading cause of death, but in under 1 years, congenital malformations, in under-5 age group, certain condition originating in the perinatal period and in children 28-days to 5-years-old, transport accidents were the most important causes of death.

Thus, for reduce mortality in children under one year, it seems necessary to pay attention to the factors related to the perinatal period and perinatal care, providing high quality services during childbirth and increasing education of mother during pregnancy. In addition, continuous monitoring of mothers to perform screening and genetic tests and assessing fetal health will be effective in reduction the birth rate of children with congenital anomalies and consequently reduction the death of children. Due to the fact that transport accidents are the most important cause of death in the 28 days to 5 years' group, this factor can be controlled through education to families and children using the capacity of public media, kindergartens and etc.

Finally, to improve the health of all children, ensuring universal access to quality care, vaccination, safe water, healthy and nutritious food and safe housing, proper education, social security and other social services is crucial. In addition, investing in women's health and education and empowering them by focusing on the most disadvantaged groups as well as increasing the level of awareness of health workers is essential (31, 38).

To our knowledge, this is the first systematic review on under- 5 mortality based on ICD-10 that focused on four groups, and covered the whole country. In addition, all studies conducted in the country were reviewed for this survey, but to select the highest quality articles, quality assessment was performed and poor quality articles were excluded. Despite these strengths, issues such as the classification of age groups under 5 years and lack of studies conducted in the country based on ICD-10 were the most important limitations of this study and to overcome these issues, appropriate measures were taken as mentioned before.

In review of studies conducted in Iran, we faced with problems in categorizing causes based on age grouping. So that some studies considered age groups that were outside the classification of the World Health Organization for under 5 children. Therefore, we had to change the grouping to avoid losing these studies. In addition, in many studies, some causes of death were incomplete, so that they were not based on ICD-10, and all of these causes categorized by researchers.

\section{Abbreviations}

MDGs: Millennium Development Goals; SDGs: Sustainable Development Goals; NMR: the neonatal mortality rate; IMR: infant mortality rate; U5MR: under five mortality rate; ICD-10: International Classification of Diseases; XS: Cross sectional; DESCR: descriptive; LR: logistic regression; X2: chi-squared test; Congenital abnormalities: Congenital malformations, deformations, and chromosomal abnormalities; Blood diseases: Diseases of the blood and blood-forming organs and certain disorders involving the immune mechanism; REM: Remainder; Fetal growth disorders: Disorders related to length of gestation and fetal growth; Metabolic diseases: Endocrine, nutritional and metabolic diseases; REM of respiratory diseases: Remainder of diseases of the respiratory system.

\section{Declarations}

\section{Ethics approval and consent to participate}

Not applicable

\section{Consent for publication}

Not applicable

\section{Availability of data and materials}

The datasets used and/or analyzed during the current study are available from the corresponding author on reasonable request. 
The authors declare that they have no competing interests.

\section{Funding}

No funding to declare

\section{Authors' contributions}

B.K., M.T. developed the review protocol and designed search criteria and strategy. B.K. and M.A. contributed searching, performing the title/abstract screening of the records, extracting data and to the writing up of the manuscript. M.T. provided general supervision on all the stages and commented on the paper draft.

\section{Acknowledgements}

We would like to thank the people who gave insightful comments on our manuscript.

\section{Authors' information}

1- Ph.D. Candidates in Department of Health Management and Economics. School of Public Health. Tehran University of Medical Sciences, Tehran, Iran.

2- Assistant Professor, Department of Health Management and Economics. School of Public Health. Tehran University of Medical Sciences, Tehran, Iran.

\section{References}

1. Houweling TA, Kunst AE, Borsboom G, Mackenbach JP. Mortality inequalities in times of economic growth: time trends in socioeconomic and regional inequalities in under 5 mortality in Indonesia, 1982-1997. Journal of Epidemiology \& Community Health. 2006; 60(1):8-62.

2. WHO H, Unicef. Monitoring maternal, newborn and child health: understanding key progress indicators: Countdown to 2015 . World Health Organization. 2011.

3. Ahmad OB, Lopez AD, Inoue M. The decline in child mortality: a reappraisal. Bulletin of the World Health Organization. 2000;78:1175-91.

4. Bereka SG, Habtewold FG, Nebi TD. Under-Five Mortality of Children and its Determinants in Ethiopian Somali Regional State, Eastern Ethiopia. Health Science Journal. 2017;11(3).

5. United Nations Inter-agency Group for Child Mortality Estimation (UN IGME). Levels \& Trends in Child Mortality: Report 2018, Estimates developed by the United Nations Inter-agency Group for Child Mortality Estimation. United Nations Children's Fund, New York. 2018.

6. Comparison of under-five child mortality rate in villages of health houses in East Azarbaijan province in 1993 and 2003. Medical Journal of Tabriz University of Medical Sciences. 2006(28):2: 113-17.

7. Keeley B, Little C. The State of the Worlds Children 2017: Children in a Digital World: ERIC; 2017.

8. Bryce J, Boschi-Pinto C, Shibuya K, Black RE, Group WCHER. WHO estimates of the causes of death in children. The Lancet. 2005;365(9465):1147-52.

9. Rao C, Adair T, Kinfu Y. Using historical vital statistics to predict the distribution of under-five mortality by cause. Clinical medicine \& research. 2011;9(2):66-74.

10. World Health Organization. International statistical classification of diseases and related health problems: 10th revision (ICD-10). 10th revision, edition 2010.

11. United Nations Inter-agency Group for Child Mortality Estimation (UN IGME), 'Levels \& Trends in Child Mortality: Report 2018, Estimates developed by the United Nations Inter-agency Group for Child Mortality Estimation', United Nations Children's Fund, New York, 2018.

12. Naghibi SA, Moosazadeh M, Shojaee J. Epidemiological features of under 5 year children mortality in Mazandaran. Journal of health research in community. 2015;1(1):11-9.

13. Soori H, Rafiei E, Entezami N, Hasani J, Hossaini SM. A comparison study on rate and causes of under 5 years old deaths in Iran, eastern Mediterranean region and the world. Safety Promotion and Injury Prevention. 2016;4(1):1-8.

14. Shahraki VA, Mardani HM, Arab M, Firouzkouhi Z. Infant under 1-59 month mortality causes in Zabol. 2010.

15. Namakin K, Sharifzadeh G. The evaluation of infants mortality causes and its related factors in Birjand. Journal of Isfahan Medical School. 2009;27(95):275-82.

16. Estimates generated by the WHO and Maternal and Child Epidemiology Estimation Group (MCEE). Prepared by the Data and Analytics Section; Division of Data, Research and Policy, UNICEF. 2018. available at http://data.unicef.org 
17. Vakili R, Emami Moghadam Z, Khademi G, Vakili S, Saeidi M. Child mortality at different world regions: a comparison review. International Journal of Pediatrics. 2015;3(4.2):809-16.

18. The World Health Organization (WHO), The Office of the United Nations High Commissioner for Human Rights (OHCHR). Mortality among children under five years of age as a human rights concern.

19. Von Elm E, Altman DG, Egger M, Pocock SJ, Gøtzsche PC, Vandenbroucke JP, et al. The Strengthening the Reporting of Observational Studies in Epidemiology (STROBE) Statement: guidelines for reporting observational studies. International journal of surgery. 2014;12(12):1495-9.

20. Fraser J, Sidebotham P, Frederick J, Covington T, Mitchell EA. Learning from child death review in the USA, England, Australia, and New Zealand. The Lancet. 2014;384(9946):894.

21. Chiabi A, Nguefack S, Mah E, Nodem S, Mbuagbaw L, Mbonda E, et al. Risk factors for birth asphyxia in an urban health facility in cameroon. Iran J Child Neurol. 2013;7(3):46-54.

22. McKenzie HI, Lovell HG, Standard KL, Miall WE. Child mortality in Jamaica. The Milbank Memorial Fund Quarterly. 1967;45(3):303-20.

23. Hockenberry/Wilson. Wong's Nursing Care of Infants and Children2007.

24. Cunningham F, Macdonald P, Gant N, Leveno KG. LC; Hankins, GDV \& CLARK, SL Williams Obstretrics. Connecticut: Appleton \& Lange. International Edition. 1997.

25. Lorente C, Cordier S, Goujard J, Aymé S, Bianchi F, Calzolari E, et al. Tobacco and alcohol use during pregnancy and risk of oral clefts. Occupational Exposure and Congenital Malformation Working Group. American Journal of Public Health. 2000;90(3):415.

26. Tomatır A, Demirhan H, Sorkun H, Köksal A, Özerdem F, Cilengir N. Major congenital anomalies: a five-year retrospective regional study in Turkey. Genetics and Molecular Research. 2009;8(1):19-27.

27. Walker CLF, Rudan I, Liu L, Nair H, Theodoratou E, Bhutta ZA, et al. Global burden of childhood pneumonia and diarrhoea. The Lancet. 2013;381(9875):1405-16.

28. Pearce N, Aït-Khaled N, Beasley R, Mallol J, Keil U, Mitchell E, et al. Worldwide trends in the prevalence of asthma symptoms: phase III of the International Study of Asthma and Allergies in Childhood (ISAAC). Thorax. 2007;62(9):758-66.

29. Marciniuk D, Ferkol T, Nana A, de Oca MM, Rabe K, Billo N, et al. Respiratory Diseases in the World. Realities of today opportunities for tomorrow. African Journal of Respiratory Medicine Vol. 2014;9(1).

30. Van de volksgezondheid gh. Informatie voor artsen met betrekking tot de wet op de lijkbezorging 1991. Ghi-bulletin rijswijk: staatstoezicht op de volksgezondheid. 1991.

31. World Health Organization. Mortality among children under five years of age as a human rights concern. Office of the United Nations High Commissioner for Human Rights Palais des Nations CH 1211 Geneva 10 - Switzerland. 2016.

32. Delbarpoor Ahmadi S, Tajedini F, Ehdaievand F, Moghimi Dehkordi B, Farsar AR, Torkaman Nejad S. Review of injuries leading to death in children aged 1 to59 months in the area covered by shahid beheshti university of medical sciences from march 2011-march 2013. Journal of safety promotion and injury prevention. 2014;1(4).

33. Nikniaz A, Tajadini N. Assessing the causes of under-five mortality in the health service of rural Azarbayejan. Med J Tabriz. 2006;28(2):113-7.

34. Mokdad AH, Marks JS, Stroup DF, Gerberding Actual causes of death in the United States, 2000. Jama. 2004;291(10):1238-45.

35. Jafroodi M, Ghandi Y. Epidemiologic evaluation of pediatric malignancies in 17 shahrivar hospital. Journal of Guilan University of Medical Sciences. 2009;17(68):14-21.

36. Rose P, Yates P. Quality of life experienced by patients receiving radiation treatment for cancers of the head and neck. Cancer Nursing. 2001;24(4):255-63.

37. Nakhzari-Moghaddam M, Yavari P, Abadi A, Rostami-Gooran N. Association of socioeconomic risk factors with under 5-year mortality in Zabol, Iran, during 2011-2015. Medical journal of the Islamic Republic of Iran. 2019;33:61.

38. Soori H, Rafiei E, Entezami N, Hasani J, Hossaini SM. A comparison study on rate and causes of under 5 years old deaths in Iran, eastern Mediterranean region and the world. Irtiqā-yi īminī va pīshgīrī az mașdūmiyat/ha (ie, Safety Promotion and Injury Prevention). 2016;4(1):1-8.

39. Dadipoor S, Alavi A, Ziapour A, Safari-Moradabadi A. Factors Involved in the Mortality of Infants under the Age of One Year in Bandar AbbasIran: A Document-Based Study. International Journal of Pediatrics. 2018;6(4):7519-27.

40. Ataey A, Alipour A, Khodakarim S, Khosravi A. Epidemiology of Under-5 Mortality Rate in Ardabil Province, Iran 2015. Journal of Mazandaran University of Medical Sciences. 2019;28(168):160-5.

41. Alipour A, Ghadiri SA, Khazaei L. Estimation of deaths in under one-year children in Mazandaran province, north of Iran, using hospital information. Iranian Journal of Epidemiology. 2018;14(2):144-52.

42. Behnampoor M, Havasian MR, Sargolzaei N, Mahmoodi Z, Salarzaei M, Mohamadi J. Investigating The Mortality Causes Of 1-59 Months Babies Of Village From 2012 To 2015, Zahedan, Iran. Indo American Journal of Pharmaceutical 2017;4(5):1079-84.

43. Izadi N, Shetabi H, Bakhtiari S, Janatalmakan M, Parabi M, Ahmadi K. The Rate and Causes of Infant Mortaliry in the Hospitals of Kermanshah Province During 2011-2014. Journal of Rafsanjan University of Medical Sciences. 2016. 15(2).38-129. 
44. Heidarnia MA, Abadi A, Fsmaeil Motlagh M, Heidarzadeh M, Habibelahi A, Raji F. Profile of neonatal mortality in Iran in 1391. Tehran University Medical Journal TUMS Publications. 2016;74(7):475-82.

45. Ghorat F, Ghafarzadeh R, Esfehani RJ. Perinatal mortality and its associated risk factors: A study in the north-east of Iran. Iranian Journal of Neonatology. 2016;7(1):47-51.

46. Gharavi A, Shoraka H, Sofizadeh A, Katuli H. Neonatal mortality risk factors in Maraveh Tapeh County in Golestan province, north of Iran (2011-13). Journal of Gorgan University of Medical Sciences. 2016;18(1).

47. Evazpoor A, Edalati A, Hypponen E, Fararouei M, Parisai Z. Deaths of children aged under 5 years and related factors in the Islamic Republic of Iran: a population-based case-control study. EMHJ-Eastern Mediterranean Health Journal. 2016;22(6):368-74.

48. Astaraki P, Mahmoudi G, Ahadi M, Almasi V. The reasons of death among children and adolescents in Lorestan Province, West of Iran, from 2007 to 2014. Int J Med Toxicol Forensic Med. 2016;6(2):65-70.

49. Ghasemi F, Vafaenasab M, Ebrahimi FM, Sardadvar N, Zare M. Evaluating rate and causes of perinatal mortality in hospitals of Yazd province in 2012. 2015.

50. Deihim Z, Aghababaeian H. Evaluation of Factors Associated with Mortality in Neonate's and Children Aged 1-59 Months in Dezful City (2009-2014). Iranian Journal of Pediatric Nursing. 2015.

51. Askari NA, Fallahzadeh AH, Fallah MH. Examining the Factors Related to Mortality Amongst One Year Old and Younger Children in Yazd City During 2011 to 2013 Period. 2015.

52. Tajedini F, Ehdaievand F, Farsar AR. Epidemiological features of children mortality in the area covered by Shahid Beheshti university of medical sciences in 2012. Journal of Clinical Nursing and Midwifery. 2014;3(1).

53. Rahmani K, Zokaei M, Bidarpoor F, Babahajiani S, Nessaei P, Moradi G. Children mortality rate trend in kurdistan province during 2007 to 2011. Iranian Journal of Epidemiology. 2014;10(1):65-72.

54. Forouzanfar MH, Sepanlou SG, Shahraz S, Dicker D, Naghavi P, Pourmalek F, et al. Evaluating causes of death and morbidity in Iran, global burden of diseases, injuries, and risk factors study 2010. Arch Iran Med. 2014;17(5):304-20.

55. Ansari-Moghaddam A, Sadeghi-Bojd S, Imani M, Movahedinia S, Pourrashidi A, Mohammadi M. A multivariate analysis of factors associated with infant mortality in South-East of Iran. J Pak Med Assoc. 2014;64(10):1123-6.

56. Rahbar M, Ahmadi M, Lornejad HR, Habibelahi A, Sanaei-Shoar T, Mesdeaghinia Mortality causes in children 1-59 months in Iran. Iranian Journal of Public Health. 2013;42(SUPPL 1):93-7.

57. Hadavi M, Alidalaki S, Abedininejad M, Akhavan S. Etiologies and contributing factors of perinatal mortality: a report from southeast of Iran. Taiwan J Obstet Gynecol. 2011;50(2):145-8.

58. Nojomi M, Naserbakhat M, Ramezany M, Anbary K. Under-5 year mortality: Result of in-hospital study, Tehran, Iran. Acta Medica Iranica. 2009;47(4):319-24.

59. Majlessi F. Study of the causes of mortality in children under 5 years of age in Chaharmahal and Bakhtiyari province, Iran. Iranian Journal of Public Health. 2000;29.

60. Mobaseri S. The prevalence of stillbirth and infant mortality: Maternal and neonatal factors. Preventive Care in Nursing \& Midwifery Journal. 2016;6(3):82-9.

61. Zamanian L. The rate and causes of neonatal mortality in Hamadan province, 2012. Avicenna Journal of Nursing and Midwifery Care. 2016;24(4):281-300.

62. Mohaghighi P, Hashemzadeh Isfahani M, Mousavi Kani K. Determining the frequency of prenatal factors in infant mortality in Tehran during 2009-2010. Razi Journal of Medical Sciences. 2013;19(103):41-7.

63. Bahman Bijari B, Niknafs P, Maddahiyan S. Causes of neonatal mortality in kerman province in 1387-(2008-2009). Journal of Urmia University Medical Sciences. 2012;22(6):501-6.

64. Javanmardi Z, Beygi M, Ghodousi A. Investigating about the causes of neonates'death in the hospitals of isfahan province. 2010.

\section{Tables}

Table1: Sources of searches and search terms and the number of studies retrieved 


\begin{tabular}{|c|c|c|c|c|c|c|c|c|}
\hline Finalincluded & $\begin{array}{l}\text { After } \\
\text { abstract } \\
\text { check }\end{array}$ & $\begin{array}{l}\text { After } \\
\text { title } \\
\text { check }\end{array}$ & $\begin{array}{l}\text { Publication } \\
\text { identified }\end{array}$ & $\begin{array}{l}\text { Key words and } \\
\text { MeSH }\end{array}$ & Database/journals & Sources & Searching & \\
\hline 6 & 15 & 33 & 138 & $\begin{array}{l}\text { ("Child Mortality" } \\
\text { [Mesh]) OR ("Infant } \\
\text { Mortality"[Mesh]) OR } \\
\text { ("Neonatal Mortality" } \\
\text { [Mesh]) OR ("Post } \\
\text { neonatal Mortality" } \\
\text { [Mesh]) AND } \\
\text { Cause[Title/Abstract] } \\
\text { AND Iran } \\
\text { [Title/Abstract] AND } \\
\text { English[lang] }\end{array}$ & Database & PubMed & \multirow[t]{6}{*}{ International } & \multirow[t]{6}{*}{$\begin{array}{l}\text { Electronic } \\
\text { Searching }\end{array}$} \\
\hline 5 & 16 & 54 & 447 & \multirow{3}{*}{$\begin{array}{l}\text { TITLE-ABS/Title, } \\
\text { abstract, keywords: } \\
\text { ("Child Mortality") OR } \\
\text { ("Infant Mortality") } \\
\text { OR ("Neonatal } \\
\text { Mortality") OR ("Post } \\
\text { neonatal Mortality") } \\
\text { OR ("newborn } \\
\text { Mortality") OR U5MR } \\
\text { AND Cause* AND } \\
\text { Iran }\end{array}$} & Database & Scopus & & \\
\hline 3 & 12 & 30 & 36 & & Database & $\begin{array}{l}\text { Web of } \\
\text { Science }\end{array}$ & & \\
\hline 5 & 27 & 61 & 57 & & Search engine & $\begin{array}{l}\text { Google } \\
\text { scholar }\end{array}$ & & \\
\hline 0 & 0 & 0 & 2 & Child* AND Iran & Database & $\begin{array}{l}\text { Cochrane } \\
\text { library }\end{array}$ & & \\
\hline 2 & 14 & 31 & 39 & $\begin{array}{l}\text {-translation of } \\
\text { "under-five mortality" } \\
\text { and its various } \\
\text { synonyms in Farsi- } \\
\text { all studies about } \\
\text { child mortality in } \\
\text { English languages }\end{array}$ & Search engine & Google & & \\
\hline 6 & 26 & 34 & 39 & \multirow{6}{*}{$\begin{array}{l}\text { translation of "under- } \\
\text { five mortality" and } \\
\text { its various } \\
\text { synonyms in Farsi }\end{array}$} & Database & SID & \multirow[t]{6}{*}{ National } & \\
\hline 0 & 2 & 4 & 4 & & Database & Maglran & & \\
\hline 3 & 14 & 16 & 16 & & Database & $\begin{array}{l}\text { Iranian } \\
\text { Medical } \\
\text { Articles } \\
\text { Bank }\end{array}$ & & \\
\hline 0 & 1 & 1 & 1 & & Journal & $\begin{array}{l}\text { Journal of } \\
\text { Pediatric } \\
\text { nursing }\end{array}$ & & \\
\hline 0 & 1 & 1 & 2 & & Journal & $\begin{array}{l}\text { Acta Medica } \\
\text { Iranica }\end{array}$ & & \\
\hline 0 & 0 & 0 & 1 & & Journal & $\begin{array}{l}\text { Iranian } \\
\text { Journal of } \\
\text { Child } \\
\text { Neurology }\end{array}$ & & \\
\hline 0 & 2 & 3 & 4 & $\begin{array}{l}\text { translation of "under- } \\
\text { five mortality" and } \\
\text { its various } \\
\text { synonyms in Farsi }\end{array}$ & - & $\begin{array}{l}\text { Bibliography } \\
\text { of the } \\
\text { included } \\
\text { papers }\end{array}$ & \multirow{3}{*}{\multicolumn{2}{|c|}{ Hand Searching }} \\
\hline 0 & 5 & 15 & 29 & & - & Thesis & & \\
\hline 0 & 1 & 1 & 2 & & & $\begin{array}{l}\text { Research } \\
\text { Project }\end{array}$ & & \\
\hline 30 & 136 & 284 & 817 & - & & Total & & \\
\hline
\end{tabular}

Table 2: Summary of characteristics and findings of the included studies (ordered chronologically) 
Ref.language Sample, setting,time, Findings

design, analysis

Quality

score $(0-$

22)

Nakhzari- $\quad \mathrm{N}=1334$ Zabol, Sistan \& Moghaddam, Baluchistan province,

et al.2019 2011-2016DESCR-XS

(37)English study/ $\chi 2$ test, $t$ test and

Univariate LR

0-28 day: Fetal growth disorders (49.9\%), REM of respiratory diseases $(11.7 \%)$, Congenital abnormalities (11.5\%), Certain conditions originating in the perinatal period (4.6\%), Bacterial sepsis of newborn (3.6\%)Transport accidents (2.1\%), Blood diseases $(0.8 \%)$, Diseases of the circulatory system (3.8\%), Less prevalent causes $(12 \%)$

17
0 to 1 year: Congenital abnormalities (17.9\%), REM of respiratory diseases (15\%), Disorders relating to length of gestation and fetal growth (2.9\%), Certain infectious and parasitic diseases (7.7\%), Transport accidents (10.1\%), Blood diseases $(2.9 \%)$, Diseases of the circulatory system (11.6\%), Diseases of the digestive system $(9.2 \%)$, Metabolic diseases (0.5\%), All other diseases (0.5\%), Less prevalent causes $(19.3 \%)$

28 days to 5 years: Transport accidents (43.6\%), Diseases of nervous system (13.8\%), Congenital abnormalities (8.5\%), Certain infectious and parasitic diseases (6.4\%), Diseases of the digestive system (7.4\%), Neoplasm (5.3\%), REM of respiratory diseases (2.1\%), All other diseases (1.1\%), Less prevalent causes $(11.8 \%)$

Age under 5 : Congenital abnormalities (13\%), REM of respiratory diseases (11.4\%), All other external causes $(0.9 \%)$, Certain conditions originating in the perinatal period (2.5\%), Diseases of the circulatory system (3.8\%), Certain infectious and parasitic diseases (5.2\%), All other diseases (4.4\%), Diseases of nervous system (6.9\%), Transport accidents (9.5\%), Diseases of the digestive system (4.8\%), Blood diseases $(1.2 \%)$, Less prevalent causes $(25.6 \%)$

0-28 day: Bacterial sepsis of newborn (25.1 REM of respiratory diseases (23.3\%), Diseases of the circulatory system (18.3\%), Fetal growth disorders (17.5\%), Less prevalent causes $(15.8 \%)$

0 to 1 year: Fetal growth disorders (30.2\%), All other diseases (24.3\%), Bacterial sepsis of newborn (15.1\%), Diseases of the circulatory system (13.4\%), Pneumonia (9.2\%), REM of respiratory diseases (7.5\%)

city, 2015

2016Retrospective and XS DESCR-analytic study/ X2 test

\section{Ataey, et}

al.2018

(40)Farsi

$\mathrm{N}=553$ Ardabil province, 2011-2015DESCRanalytical study/ $\chi 2$ test

Alipour, et al.2018

(41)Farsi

$\mathrm{N}=764$ Mazandaran province, 2011-2014XS study/ t test

Age under 5: Congenital abnormalities (30.9\%), Certain conditions originating in the

perinatal period (12.3\%), Blood diseases (8.5\%), Transport accidents (8.3\%)

Neoplasms (7.4\%), All other external causes (7.4\%), REM of respiratory diseases $(6.9 \%)$, Diseases of nervous system (5.1\%), Less prevalent causes $(13.2 \%)$

0 to 1 year: Remainder of prenatal condition (45.8\%), Congenital abnormalities (19.7\%), REM of respiratory diseases (14.1\%), All other external causes (3.8\%), Bacterial sepsis of newborn (3.1\%), Certain conditions originating in the perinatal period (1.6\%), Metabolic diseases (1.3\%), Blood diseases (1.3\%), Diseases of the digestive system (0.6\%), Neoplasms (0.3\%), Disease of nervous system (0.3\%), Less prevalent cause $(8.1 \%)$

Behnampoor, $\quad \mathrm{N}=1252$ Zahedan city,

et al.2017

2012-2015XS study/

Age under 5: Certain conditions originating in the perinatal period (29.8\%), Transport

(42) English x2 test

Accidents (17.3\%), REM of respiratory diseases (13.2\%), Congenital abnormalities

(6\%), Diseases of the circulatory system (2.4\%), Diseases of the nervous system (1.1\%), Metabolic diseases (0.8\%), Less prevalent cause $(30.2 \%)$

Izadi, et $\quad \mathrm{N}=435 \mathrm{Kermanshah}$

al.2016

(43)Farsi province, 2011-2014XS studyDESCR statistics/ X2 test

Age under 5: Transport Accidents (18.6\%), REM of respiratory diseases (14.9\%), Diseases of the circulatory system (12.1\%), Congenital abnormalities (10.1\%), All other diseases (2.9\%), Metabolic diseases (5.9\%), Diseases of the nervous system (5.9\%), Diseases of digestive system (5.7\%), Blood diseases (4.1\%), Less prevalent cause $(19.8 \%)$

Heidarnia, et $\quad \mathrm{N}=11693$ Iran, 2012XS al.2016 study

0-28 day: Certain conditions originating in the perinatal period $(77.9 \%)$, Congenital abnormalities (20.8\%), Less prevalent cause (1.3\%)

0-28 day: Intrauterine hypoxia and birth asphyxia (35.5\%), Bacterial sepsis of

Ghorat, et

al.2016

$\mathrm{N}=$ 282Sabzevar city, newborn (11.3\%), REM of respiratory diseases (44.5\%), Less prevalent cause (8.7\%)

2012,2013DESCR-XS studyindependent sample t-test, and Х2 test /Fisher's exact test

\section{Kose}

Gharavi, et

al.2016

(46)Farsi

$\mathrm{N}=52 \mathrm{Maraveh}$ Tapeh city, 2011-2013Casecontrol study/ X2 test and LR

Evazpoor, et al.2016

$\mathrm{N}=186$ Kohgiluyeh and (47)English Boyerahmad Province, 2011,2012DESCRanalytical and XS study Student's $t$ and X2 test,multivariate LR
0-28 day: Fetal growth disorders (46.2\%), Congenital abnormalities (15.4\%), REM of respiratory diseases (13.5\%), Bacterial sepsis of newborn (7.7\%), Less prevalent cause $(17.2 \%)$

0-28 day: Fetal growth disorders (50.9\%), Congenital abnormalities (29.2\%), REM of respiratory diseases $(9.4 \%)$, Less prevalent cause (10.5\%)

0 to 1 year: Congenital abnormalities (63.2\%), REM of respiratory diseases (10.5\%), Less prevalent cause (26.3\%)

0

7

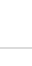

7

6


28 days to 5 years: Congenital abnormalities (34.1\%), REM of respiratory diseases (2.4\%), Less prevalent cause (63.5\%)

Age under 5: Fetal growth disorders (29\%), Congenital abnormalities (37.6\%), REM of respiratory diseases $(8.1 \%)$, Less prevalent cause $(25.3 \%)$

$\begin{array}{lll}\text { Astaraki, et } & \mathrm{N}=345 \mathrm{~L} \text { orestan } & \text { Age under 5: Transport Accident (53.9\%), All other external causes (9.8\%), Fetal } \\ \text { al.2015 } & \text { province, 2007-2014XS } & \text { growth disorders (4.9\%), REM of respiratory diseases (13.6\%), Diseases of nervous } \\ \text { (48)English } & \text { study / X2 test } & \text { system (1.1\%), Less prevalent cause (16.7\%) }\end{array}$

(48)English

$\mathrm{N}=390$ Yazd province

Ghasemi, et 2012DESCR-XS

0-28 day: Certain conditions originating in the perinatal period (52.3\%), Congenital

al.2015 studyDESCR statistics and LR abnormalities (46.9\%), Transport accidents (0.8\%)

(n)

(49)Farsi

\section{$\mathrm{N}=184 \mathrm{Mazandaran}$}

Naghibi, et al.2015

(12)Farsi province, 2011XS study/ DESCR statistics and $\chi 2$ test

Deihim, et al.2015 (50)Farsi
$\mathrm{N}=297$ Dezful city, 20092014XS studyDESCR statistics/ fisher and x2 test
Age under 5: REM of respiratory diseases $(26.1 \%)$, Diseases of the circulatory system

(14.7\%), Congenital abnormalities (10.3\%), Less prevalent cause (48.9\%)

0-28 day: REM of respiratory diseases (65.3\%), Congenital abnormalities (8.8\%),

Intrauterine hypoxia and birth asphyxia (8.8\%), Blood diseases $(7 \%)$, Certain infectious and parasitic diseases (5.9\%), All other external causes (1.5\%), Less prevalent cause $(6 \%)$

0 to 1 year: Congenital abnormalities (43.6\%), Certain infectious and parasitic diseases $(23.1 \%)$, REM of respiratory diseases $(17.9 \%)$, All other external causes $(5.1 \%)$, Intrauterine hypoxia and birth asphyxia (2.6\%), Diseases of the nervous system $(2.6 \%)$, All other diseases $(2.6 \%)$, Less prevalent cause $(2.5 \%)$

28 days to 5 years: Congenital abnormalities (43.6\%), Neoplasm (12.5\%), Certain infectious and parasitic diseases $(6.2 \%)$, Less prevalent cause $(37.7 \%)$
Nodoushan, et al.2015 (51)English

Tajedini F, et al.2014 (52)Farsi

Rahmani, et al.2014 (53)Farsi
$\mathrm{N}=116$ Yazd city, 20112013DESCR-Analytical StudyDESCR statistics/ fisher and $\chi 2$ test

$\mathrm{N}=383$ Tehran province, 2012,2013DESCR-XS study/ $\chi 2$ test
0 to 1 year: Certain infectious and parasitic diseases (4.3\%), Less prevalent cause $(95.7 \%)$

28 days to 5 years: Transport Accident (15.4\%), Congenital abnormalities (17.4\%) ,Neoplasm (11.2\%), REM of respiratory diseases (10.1\%), Diseases of the nervous system (8.1\%), Diseases of the digestive system (6.2\%), Blood diseases (4.7\%), Certain infectious and parasitic diseases (3.6\%), Certain conditions originating in the perinatal period $(7.8 \%)$, Less prevalent cause $(15.5 \%)$

0-28 day: Congenital abnormalities (16\%), REM of respiratory diseases (2.6\%), Certain Infectious and parasite disease (0.5\%), All other disease (0.3\%), Less prevalent cause $(80 \%)$

0 to 1 year: Congenital abnormalities (21.6\%), Transport Accident (4.8\%), REM of respiratory diseases (3.0\%), Certain Infectious and parasite disease (1.0\%), Gastro intestinal system $(0.8 \%)$, Disease of the Nervous system $(0.9 \%)$, Disease of the circulatory system $(0.6 \%)$, All other disease $(0.5 \%)$, Metabolic diseases $(0.4 \%)$, Less prevalent cause $(66.4 \%)$

Age under 5: Certain conditions originating in the perinatal period (58.8\%), Congenital abnormalities (20.6\%), Transport Accident (8\%), REM of respiratory diseases (3.3\%), Neoplasm (1.8\%), Disease of Nervous system (0.9\%), Disease of the circulatory system $(0.7 \%)$, All other disease $(0.9 \%)$, Metabolic diseases $(0.4 \%)$, Less prevalent cause $(4.6 \%)$

Forouzanfar, N=33821Iran, 1990, et al.2014 (54)English 2005, 2010Time seriesmodeling by three methods of linear, space-time smoothing and Gaussian process regression

Age under 5: Certain conditions originating in the perinatal period (37.9\%), All other external disease (0.3\%), Metabolic diseases (8.4\%), Transport accident (4.2\%), Disease of Nervous system (1.4\%), REM of respiratory diseases (2.2\%), All other disease (22.5\%), Disease of circulatory system (4.4\%), Less prevalent cause (18.7\%) $\begin{array}{ll}\text { Ansari- } & \mathrm{N}=404 Z \text { Zahedan city, } \\ \text { Moghaddam, } & \text { 2011population-based }\end{array}$ et al.2014 case-control study/ (55)English univariate and multivariate LR Congenital abnormalities (30.0\%), Intrauterine hypoxia and birth Asphyxia (13.5\%), Certain infectious and parasite disease (4.2\%), Less prevalent cause (13.1\%)

0 to 1 year: Fetal growth disorders (23.4\%), Congenital abnormalities (23.1\%), Diseases of nervous System (13.6\%), Diseases of digestive system (8.3\%), Certain infectious and parasite disease (4.9\%), Less prevalent cause $(26.7 \%)$

0 to 1 year: Congenital abnormalities (30.9\%), REM of respiratory diseases (13.9\%),
0-28 day: Fetal growth disorders (25.0\%), Bacterial sepsis of newborn (14.2\%),

Certain infectious and parasite disease $(8.8 \%)$, Diseases of the circulatory system digestive system (4.4\%), REM of Prenatal condition (3.3\%), Less prevalent cause $(21.5 \%)$
(56)English al.2013
2007,2008XS study/ DESCR statistics 
28 days to 5 years: Congenital abnormalities (13.4\%), Transport accident (40.8\%), Neoplasm (6.9\%), Diseases of nervous system (8.5\%), REM of respiratory diseases $(6.4 \%)$, Diseases of digestive system (3.5\%), Certain infectious and parasite disease $(6.2 \%)$, REM of Prenatal condition (0.1\%), Blood diseases (2.5\%), All other disease $(1.8 \%)$, Less prevalent cause $(16.1 \%)$

$\begin{array}{lll}\text { Hadavi, et } & \mathrm{N}=321 \mathrm{Rafsanjan} & 0-28 \text { day: Fetal growth disorders (63.2\%), Certain infectious and parasite disease } \\ \text { al.2010 } & \text { city,2006,2007Case } & \text { (5.7\%), Less prevalent cause (31.1\%) }\end{array}$

(57)English

control prospective

study/ $\chi 2$ test and

independent sample $t$ test

$\begin{array}{ll}\begin{array}{l}\text { Shahraki } \\ \text { Vahed, et } \\ \text { al.2010 } \\ \text { (14)Farsi }\end{array} & \begin{array}{l}\mathrm{N}=93 \mathrm{9} \text { 2007Rol city, } \\ \text { DESCR analytical study/ } \\ \mathrm{t} \text { test and } \chi 2 \text { test }\end{array} \\ \begin{array}{l}\text { Nojomi, et } \\ \begin{array}{l}\text { al.2009 } \\ \text { (58)English }\end{array}\end{array} & \begin{array}{l}\mathrm{N}=142 \text { Tehran province, } \\ \text { 2005, 2006case-control } \\ \text { study/ test }\end{array}\end{array}$

Age under 5: Transport Accidents (27\%), REM of respiratory diseases (18.3\%),

Congenital abnormalities (5.4\%), Diseases of circulatory system (8.6\%), Diseases of nervous system (2.2\%), Less prevalent cause (38.5\%)

0-28 day: Fetal growth disorders (60\%), Bacterial sepsis of newborn (6\%), Intrauterine hypoxia and birth asphyxia (9.4\%), Congenital abnormalities (5.9\%),Less prevalent cause $(18.7 \%)$

0 to 1 year: Congenital abnormalities (27.3\%), Metabolic diseases (18.2\%), Less prevalent cause $(54.5 \%)$

Age under 5: Certain conditions originating in the perinatal period (67.9\%), Diseases of the circulatory system (2.8\%), Transport Accidents (1.4\%), All other disease $(1.4 \%)$, Diseases of nervous system (0.7\%), Metabolic diseases $(2.1 \%)$, Less prevalent cause $(23.7 \%)$

$\begin{array}{ll}\text { Majlessi2000 } & \mathrm{N}=\text { 597Chaharmahal } \\ \text { (59)Farsi } & \text { Bakhtiyari province, } \\ & \text { 1992retrospective } \\ & \text { DESCR-analytical XS } \\ & \text { study/ } \chi 2 \text { test }\end{array}$

Age under 5: REM of respiratory diseases (14.4\%), Transport Accident (10.7\%), Congen
Vakilian, et al.2016 $\mathrm{N}=246$ Markazi province, (60)Farsi 2012,2013XS study /
0-28 day: Fetal growth disorders (28.9\%), Respiratory distress of newborn (21.5\%),
REM of respiratory diseases $(12.2 \%)$, Congenital abnormalities $(10.5 \%)$, Bacterial sepsis of newborn (10.4\%), REM of perinatal condition (7.5\%), Intrauterine hypoxia and birth asphyxia (8.9\%), Less prevalent cause $(0.1 \%)$
$\begin{array}{ll}\text { Oshvandi, et } & \mathrm{N}=333 \mathrm{H} \text { amedan } \\ \text { al.2014 } & \text { province, 2011DESCR- } \\ \text { (61)Farsi } & \text { analytical study/ } \mathrm{X} \text { 2 tes }\end{array}$
0-28 day: Respiratory distress of newborn (55.5\%), Bacterial Sepsis of newborn $(10.2 \%)$, Intrauterine hypoxia and birth asphyxia (8.7\%), Congenital abnormalities and t-test

$\begin{array}{ll}\text { Namakin, et } & \mathrm{N}=118 \mathrm{Birjand} \text { city, } \\ \text { al.2009 } & 2004,2005 \text { Case control } \\ \text { (15)Farsi } & \text { study/ LR }\end{array}$

0-28 day: Fetal growth disorders (54.2\%), Congenital abnormalities (17\%), Certain

(15)Farsi study/ LR

infectious and parasite disease (14.8\%), Intrauterine hypoxia and birth asphyxia $(5.3 \%)$, REM of respiratory diseases $(1.1 \%)$, Less prevalent cause $(7.6 \%)$

0 to 1 year: Congenital abnormalities (33.3\%), Metabolic diseases (16.6\%), REM of diseases of respiratory disease (12.5\%), All others disease (12.5\%), Disease of nervous system (8.3\%), Transport accident (8.3\%), Less prevalent cause (8.7\%)

$\begin{array}{ll}\text { Mohagheghi, } & \mathrm{N}=3768 \mathrm{Iran}, \\ \text { et al.2012 } & 2009,2010 X \mathrm{X} \\ \text { (62)Farsi } & \text { study/DESCR statistics }\end{array}$

0-28 day: Bacterial sepsis of newborn (78\%), Less prevalent cause (22.0\%)

Bahman $\quad \mathrm{N}=535 \mathrm{Kerman}$ province,

bijari, et 2008XS study/ DESCR

al.2010

(63)Farsi statistics

0-28 day: Fetal growth disorders (36.4\%), Intrauterine hypoxia and birth asphyxia

$(20.7 \%)$, Congenital abnormalities (13.8\%), Bacterial sepsis of newborn (13.6\%), Less prevalent cause $(15.5 \%)$

Javanmardi, $\quad \mathrm{N}=578$ Esfahan et al.2009 (64)Farsi province, 2005DESCR XS study/ DESCR statistics
0-28 day: Fetal growth disorders (44.9\%), Congenital abnormalities (19.5\%),

Respiratory distress of newborn (4.5\%), Intrauterine hypoxia and birth asphyxia $(6.2 \%)$, REM of perinatal condition $(0.2 \%)$, Less prevalent cause $(24.7 \%)$

Abbreviations: XS: Cross sectional, DESCR: descriptive, LR: logistic regression, $\chi 2$ : chi-squared test, Congenital abnormalities: Congenital malformations, deformations, and chromosomal abnormalities, Blood diseases : Diseases of the blood and blood-forming organs and certain disorders involving the immune mechanism, REM: Remainder, Fetal growth disorders: Disorders related to length of gestation and fetal growth, Metabolic diseases: Endocrine, nutritional and metabolic diseases, REM of respiratory diseases: Remainder of diseases of the respiratory system

Table 3: Number and percentages of Causes of child mortality in Iran based on originals studies based on the ICD-10. 


\begin{tabular}{|c|c|c|c|c|c|}
\hline Code & Causes of death & 0-28 Days & $0-1$ year & $0-5$ years & $\begin{array}{l}28 \text { day- } \\
\text { 5years }\end{array}$ \\
\hline P05-P08 & $\begin{array}{l}\text { Disorders relating to length of gestation and fetal } \\
\text { growth }\end{array}$ & $1096(5.9 \%)$ & $90(1.0 \%)$ & $597(1.3 \%)$ & $1(0.2 \%)$ \\
\hline J30-J98 & Remainder of diseases of the respiratory system & $738(4.0 \%)$ & $750(9.0 \%)$ & $1501(3.4 \%)$ & $42(7.8 \%)$ \\
\hline Q00-Q99 & $\begin{array}{l}\text { Congenital malformations, deformations, and } \\
\text { chromosomal abnormalities }\end{array}$ & $3141(17.0 \%)$ & $1903(22.8 \%)$ & $1326(3.0 \%)$ & $97(18.1 \%)$ \\
\hline $\begin{array}{l}\text { F01-F99, H00-H59, } \\
\text { L00-L98, M00-M99 }\end{array}$ & All other diseases & $125(0.7 \%)$ & $393(4.7 \%)$ & $11458(26.1 \%)$ & $39(7.3 \%)$ \\
\hline $\begin{array}{l}\text { P29, P35, P37, P39, } \\
\text { P70-P96 }\end{array}$ & Remainder of perinatal conditions & $10735(57.8 \%)$ & $1770(21.2 \%)$ & $1509(3.4 \%)$ & $20(3.7 \%)$ \\
\hline $100-199$ & Diseases of the circulatory system & $166(0.9 \%)$ & $339(4.0 \%)$ & $1975(4.5 \%)$ & $39(7.3 \%)$ \\
\hline A00-B99 & Certain infectious and parasitic diseases & $140(0.7 \%)$ & $469(5.6 \%)$ & $509(1.1 \%)$ & $23(4.3 \%)$ \\
\hline G00-G98 & Diseases of the nervous system & $47(0.2 \%)$ & $275(3.3 \%)$ & $842(1.9 \%)$ & $44(8.2 \%)$ \\
\hline V01-V99 & Transport accidents & $187(1.0 \%)$ & $475(5.7 \%)$ & $2213(5.0 \%)$ & $113(21.1 \%)$ \\
\hline K00-K92 & Diseases of the digestive system & $22(0.1 \%)$ & $225(2.7 \%)$ & $417(0.9 \%)$ & $31(5.8 \%)$ \\
\hline R95 & Sudden infant death syndrome & $4(0.02 \%)$ & $1(0.01 \%)$ & $5(0.01 \%)$ & $0(0.0 \%)$ \\
\hline V01-Y89 & External causes of morbidity and mortality & $12(0.1 \%)$ & $104(1.2 \%)$ & $827(1.9 \%)$ & $6(1.1 \%)$ \\
\hline D50-D89 & $\begin{array}{l}\text { Diseases of the blood and blood-forming organs } \\
\text { and certain disorders involving the immune } \\
\text { mechanism }\end{array}$ & $29(0.1 \%)$ & $138(1.6 \%)$ & $178(0.4 \%)$ & $18(3.3 \%)$ \\
\hline C00-D48 & Neoplasms & $0(0.0 \%)$ & $75(0.9 \%)$ & $612(1.4 \%)$ & $50(9.3 \%)$ \\
\hline P36 & Bacterial sepsis of newborn & $312(1.7 \%)$ & $72(0.8 \%)$ & $0(0.0 \%)$ & $2(0.3 \%)$ \\
\hline J12-J18 & Pneumonia & $5(0.02 \%)$ & $11(0.1 \%)$ & $0(0.0 \%)$ & $0(0.0 \%)$ \\
\hline P20-P21 & Intrauterine hypoxia and birth asphyxia & $315(1.7 \%)$ & $1(0.01 \%)$ & $47(0.1 \%)$ & $1(0.1 \%)$ \\
\hline P22 & Respiratory distress of newborn & $141(1.4 \%)$ & $8(0.1 \%)$ & $0(0.0 \%)$ & $0(0.0 \%)$ \\
\hline E00-E88 & Endocrine, nutritional and metabolic diseases & $25(0.1 \%)$ & $210(2.5 \%)$ & $2349(5.3 \%)$ & $15(2.8 \%)$ \\
\hline $\begin{array}{l}\text { W00-W64, W85-W99, } \\
\text { X10-X39, X50-X84, } \\
\text { Y10-Y89 }\end{array}$ & All other external causes & $2(0.01 \%)$ & $31(0.4 \%)$ & $2486(5.6 \%)$ & $2(0.3 \%)$ \\
\hline $\mathrm{X} 40-\mathrm{X} 49$ & $\begin{array}{l}\text { Accidental poisoning by and exposure to noxious } \\
\text { substances }\end{array}$ & $4(0.02 \%)$ & $3(0.03 \%)$ & $10(0.02 \%)$ & $0(0.0 \%)$ \\
\hline Q90-Q99 & $\begin{array}{l}\text { Down's syndrome and other chromosomal } \\
\text { abnormalities }\end{array}$ & $2(0.01 \%)$ & $0(0.0 \%)$ & $0(0.0 \%)$ & $0(0.0 \%)$ \\
\hline P00-P04 & $\begin{array}{l}\text { Fetus and newborn affected by maternal factors } \\
\text { and by complications of pregnancy, labor and } \\
\text { delivery }\end{array}$ & $14(0.1 \%)$ & $3(0.03 \%)$ & $4(0.0 \%)$ & $0(0.0 \%)$ \\
\hline P50-P61 & $\begin{array}{l}\text { Hemorrhagic and hematological disorders of } \\
\text { fetus and newborn }\end{array}$ & $37(0.2 \%)$ & $0(0.0 \%)$ & $0(0.0 \%)$ & $0(0.0 \%)$ \\
\hline P00-P96 & $\begin{array}{l}\text { Certain conditions originating in the perinatal } \\
\text { period }\end{array}$ & $0(0.0 \%)$ & $2(0.02 \%)$ & $12845(29.3 \%)$ & $0(0.0 \%)$ \\
\hline \multirow[t]{3}{*}{ X85-Y09 } & Assault & $0(0.0 \%)$ & $0(0.0 \%)$ & $101(0.2 \%)$ & $0(0.0 \%)$ \\
\hline & Less prevalent causes* & $1895(10.2 \%)$ & $1480(17.7 \%)$ & $5247(11.9 \%)$ & $27(5.0 \%)$ \\
\hline & Total death reviewed $(n=71244)$ & $18567(100 \%)$ & $8332(100 \%)$ & $43811(100 \%)$ & $534(100 \%)$ \\
\hline
\end{tabular}

\section{Figures}



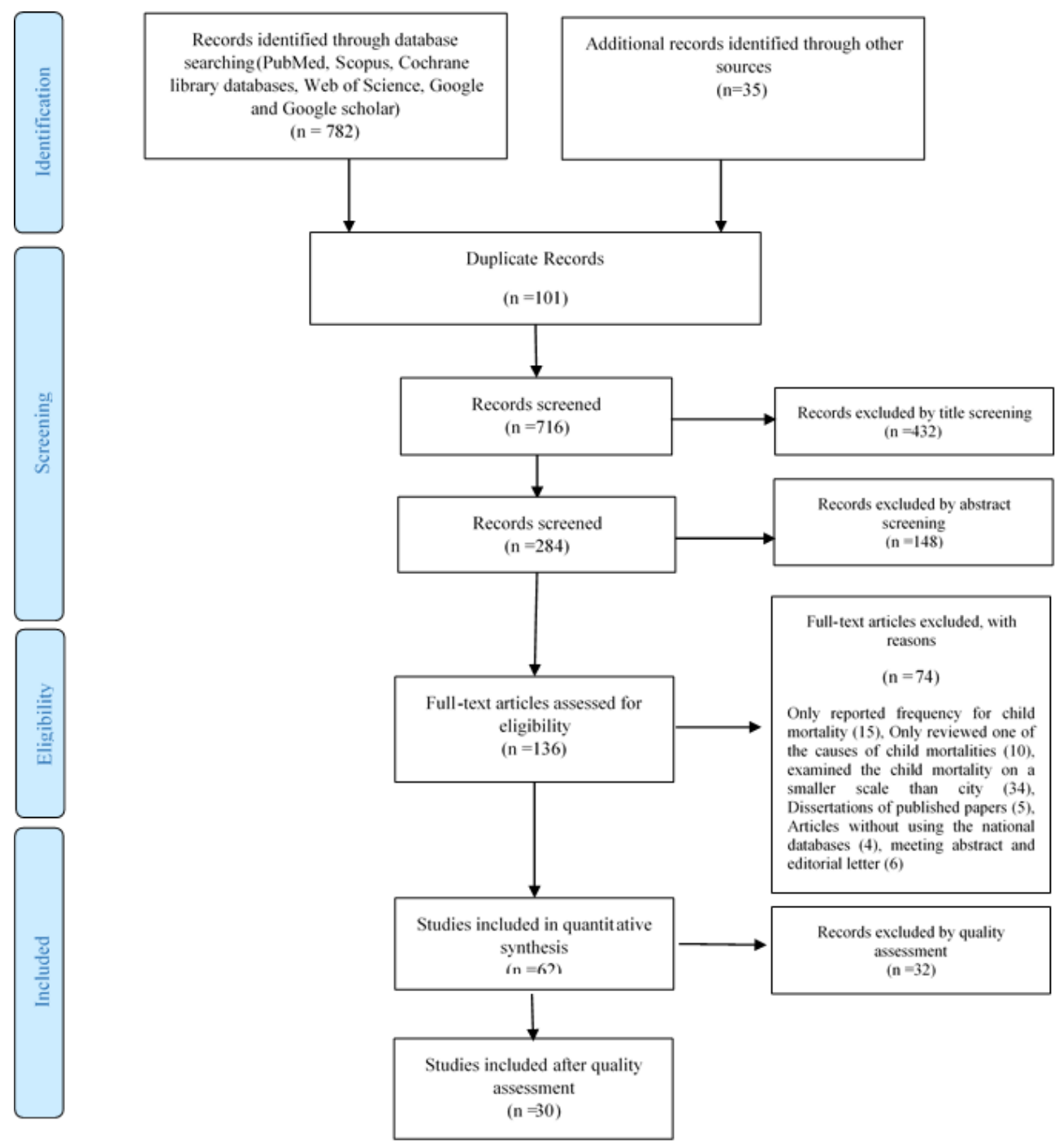

\section{Figure 1}

PRISMA flow diagram illustrating article selection and elimination

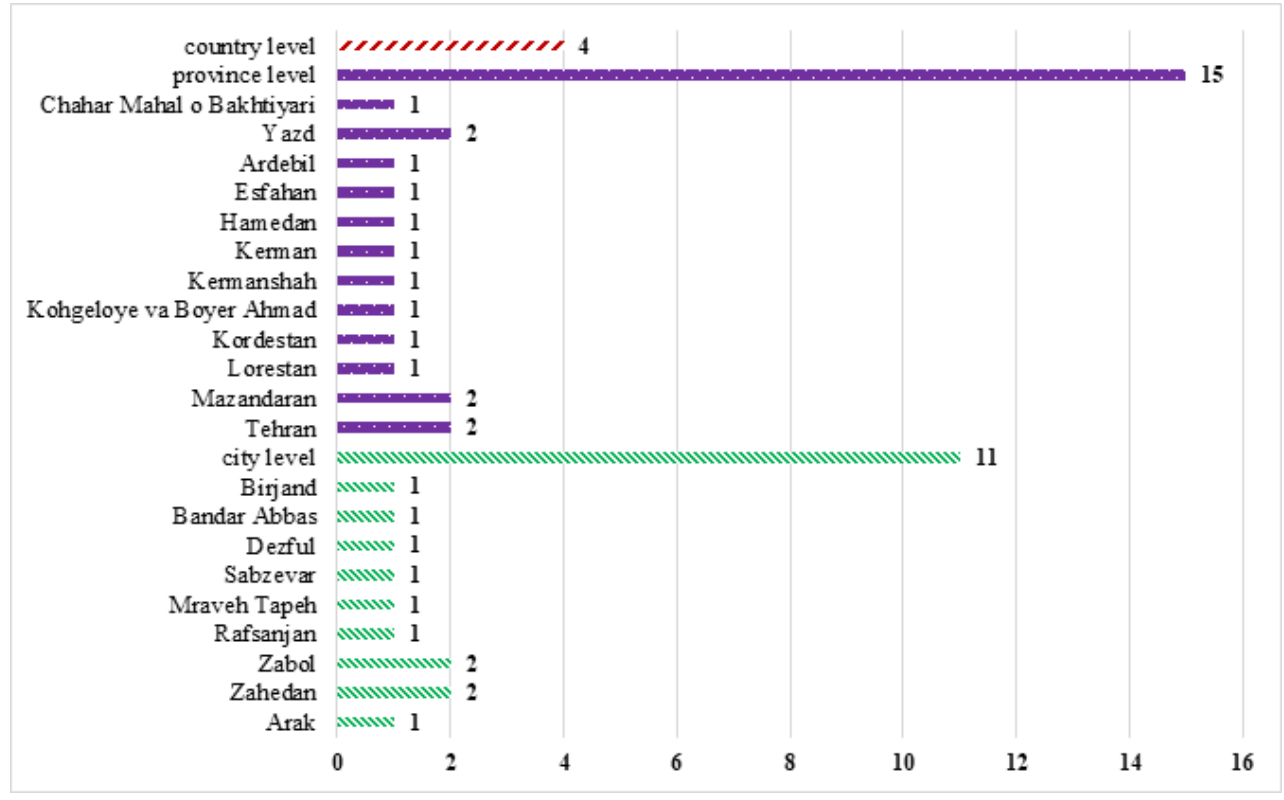

Figure 2 
Number of original studies by their study setting

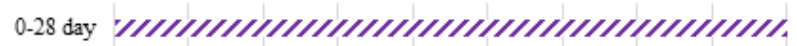

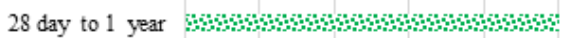

$$
0 \text { to } 1 \text { year }
$$

1 year to 5 years

28 day to 5 year

Under 5 Alm.m.

$$
\begin{array}{lllllllllll}
0 & 2 & 4 & 6 & 8 & 10 & 12 & 14 & 16 & 18 & 20
\end{array}
$$

\section{Figure 3}

Number of original studies by age group they considered

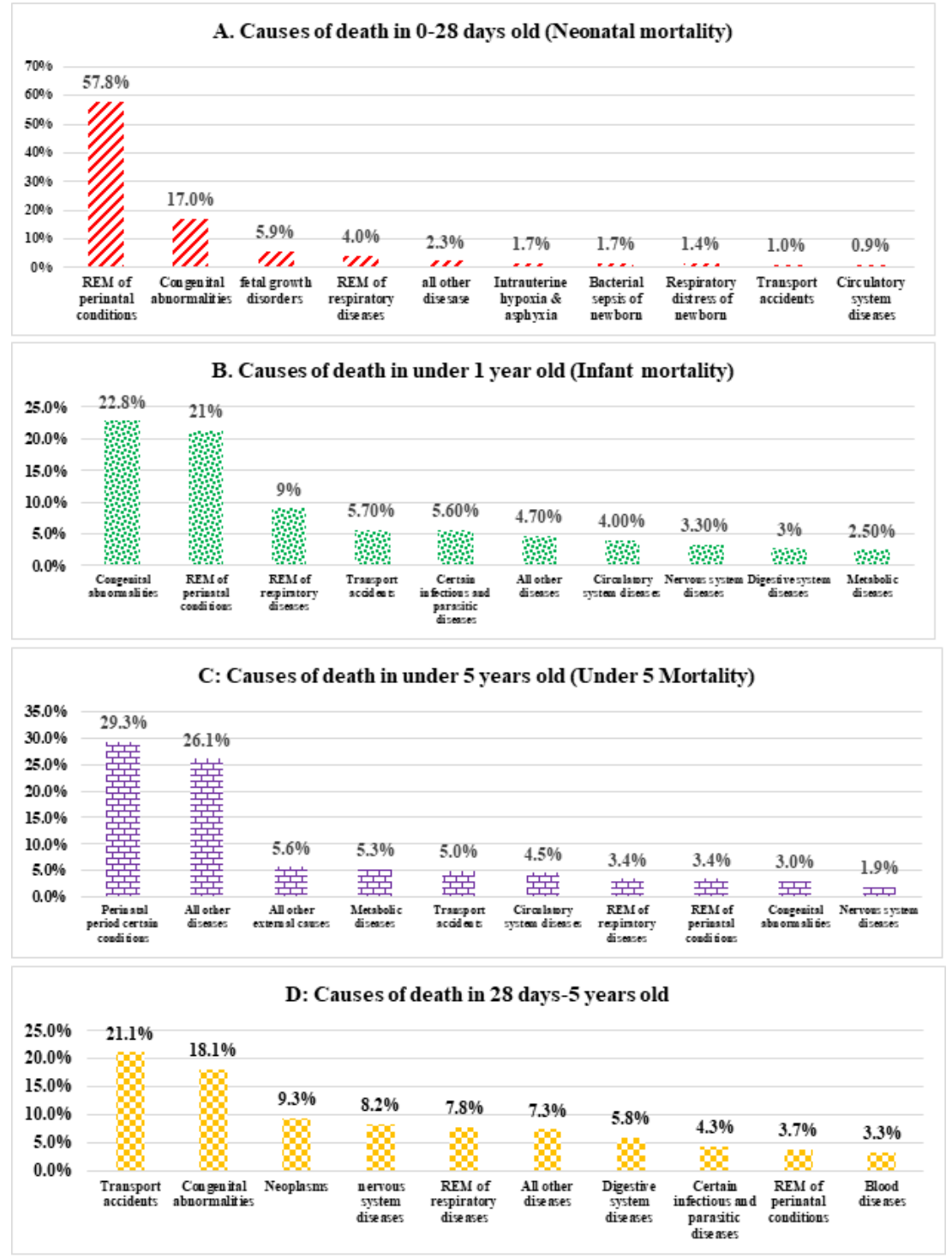

\section{Figure 4}

Major causes of child death by different age groups in Iran 

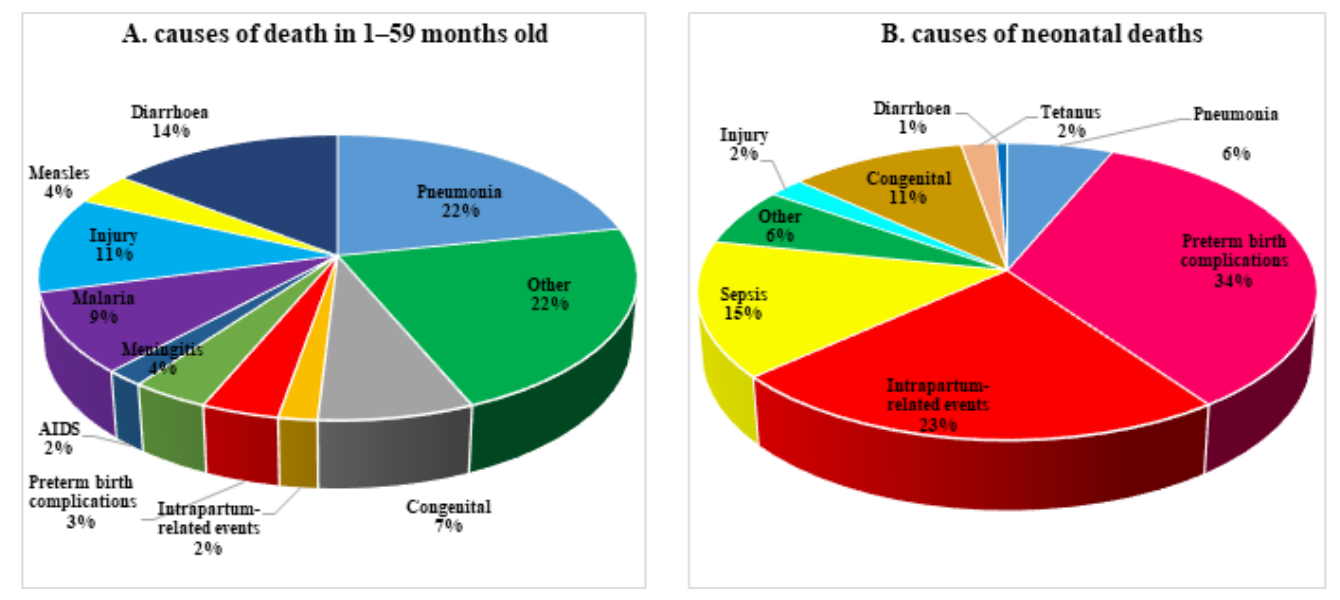

Figure 5

Major causes of neonatal and child death in the world (WHO, 2019) 